\title{
Characterization of hypersensitivity reactions reported among Andrographis paniculata users in Thailand using Health Product Vigilance Center (HPVC) database
}

Wimon Suwankesawong ${ }^{1}$, Surasak Saokaew ${ }^{2,3,4}$, Unchalee Permsuwan ${ }^{5}$ and Nathorn Chaiyakunapruk 3,6,7,8*

\begin{abstract}
Background: Andrographis paniculata (andrographis) is one of the herbal products that are widely used for various indications. Hypersensitivity reactions have been reported among subjects receiving Andrographis paniculata in Thailand. Understanding of characteristics of patients, adverse events, and clinical outcomes is essential for ensuring population safety.

This study aimed to describe the characteristics of hypersensitivity reactions reported in patients receiving andrographis containing products in Thailand using national pharmacovigilance database.

Methods: Thai Vigibase data from February 2001 to December 2012 involving andrographis products were used. This database includes the reports submitted through the spontaneous reporting system and intensive monitoring programmes. The database contained patient characteristic, adverse events associated with andrographis products, and details on seriousness, causality, and clinical outcomes. Case reports were included for final analysis if they met the inclusion criteria; 1) reports with andrographis being the only suspected cause, 2) reports with terms consistent with the constellation of hypersensitivity reactions, and 3) reports with terms considered critical terms according to WHO criteria. Descriptive statistics were used.

Results: A total of 248 case reports of andrographis-associated adverse events were identified. Only 106 case reports specified andrographis herbal product as the only suspected drug and reported at least one term consistent with constellation of hypersensitivity reactions.

Most case reports (89\%) came from spontaneous reporting system with no previously documented history of drug allergy (88\%). Of these, 18 case reports were classified as serious with 16 cases requiring hospitalization. For final assessment, the case reports with terms consistent with constellation of hypersensitivity reactions and critical terms were included. Thirteen case reports met such criteria including anaphylactic shock $(n=5)$, anaphylactic reaction $(n=4)$ and angioedema $(n=4)$. Time to development of symptoms ranged from 5 minutes to 1 day. The doses of andrographis used varied from $352 \mathrm{mg}$ to $1,750 \mathrm{mg}$. Causality assessment of 13 case reports were certain $(\mathrm{n}=3)$, probable $(n=8)$ and possible $(n=2)$.

(Continued on next page)
\end{abstract}

\footnotetext{
* Correspondence: nathorn.chaiyakunapruk@monash.edu

${ }^{3}$ Center of Pharmaceutical Outcomes Research (CPOR), Department of

Pharmacy Practice, Faculty of Pharmaceutical Sciences, Naresuan University,

Phitsanulok, Thailand

${ }^{6}$ School of Pharmacy, Monash University Malaysia, Selangor, Malaysia

Full list of author information is available at the end of the article
} 
(Continued from previous page)

Conclusions: Our findings suggested that hypersensitivity reactions have been reported among patients receiving Andrographis paniculata. Healthcare professionals should be aware of this potential risk. Further investigation of the causal relationship is needed; meanwhile including hypersensitivity reactions for andrographis product labeling should be considered.

Keywords: Andrographis paniculata, Database, Health Product Vigilance Center (HPVC), Hypersensitivity Reactions, Thailand

\section{Background}

Andrographis paniculata (andrographis) is one of the herbal products that have been widely used for a variety of medical purposes. It is widely found and cultivated in tropical and subtropical Asia, South-East Asia, and India. The leave part has been used traditionally to treat fever, and infection especially those related to respiratory tract infections [1]. A systematic review of safety and efficacy of andrographis from seven double-blinded, controlled trials indicated a superiority in alleviating the subjective symptoms of uncomplicated upper respiratory tract infection of andrographis compared with placebo [1]. Mild and infrequent adverse events were reported following its use [1]. However, the interpretation of safety data should be cautious from efficacy trials due to of the absence of rigorous data collection on adverse events [1]. Additionally, the Uppsala Monitoring Centre (UMC) which maintains the WHO international pharmacovigilance programme in collaboration with other 112 countries around the world collected 19 case reports of suspected adverse reactions from andrographis containing oral products [2]. Of those, 17 reports concerned acute hypersensitivity reactions which included 7 reports of anaphylaxis. Even though andrographis product is often perceived as a safe herbal product with minor adverse effects, it is recommended that a warning be included in the product information of andrographis containing oral products [2].

In Thailand, a single ingredient product of andrographis in oral preparation forms such as capsule, tablet and bolus has been listed in the National List of Essential Medicines (NLEM) for use in the indication of non-infectious diarrhea and pharyngotonsillitis since 1999 [3]. Its indication has been expanded to common cold since 2006 [4,5]. To ensure its safety, an intensive monitoring programme was developed as a part of NLEM standard process in order to surveillance for adverse events that might occur. The program was responsible by The Health Product Vigilance Center (HPVC), which was established under the Thai Food and Drug Administration, Ministry of Public Health in 1983 (http://thaihpvc.fda.moph.go.th). Under this intensive monitoring programme, 1,873 patients using andrographis oral containing products (199 during 2001-2003, and 1,674 during 2007-2009) were reported that andrographis could possibly cause various adverse events such as rash, pruritus, breath discomfort, cough, peeling skin, fatigue, nausea, gastric discomfort, anorexia, headache and palpitation [6,7]. It should be noted that direct causation has not been substantiated and other contributing factors could be playing a role in adverse events being reported. After this period, the HPVC has continued monitoring the safety of this product through spontaneous reporting system. Despite some limitations such as under-reporting and limited quality of reports, the spontaneous reporting system is still a valuable mechanism in identifying adverse events and their characteristics which may lead to regulatory actions to improve patient safety [8-11].

Thai Vigibase has been developed by the HPVC as the Thai national database collecting all case reports submitted from the spontaneous reporting system or intensive monitoring programmes [12]. Intensive monitoring programmes were undertaken to promote the reporting of adverse events associated with herbal product use. After a total of five single herbal products were included in the Thai NLEM in 1999, a 2-year intensive monitoring programme of these products was launched in the year 2000. In addition, an intensive monitoring programme was initiated by the Department for Development of Thai Traditional and Alternative Medicine (which is responsible for promoting the use of herbal products in Thailand). This programme focused on four single herbal products (Cissus quadrangularis [Veld grape], Centella asiatica [Pennywort], Derris scandens [Jewel vine], Momordica charantia [Bitter melon]) that were under consideration for inclusion in the NLEM. Data collected under this programme will be crucial information used for considering whether these products are to be listed in NLEM. Suspected adverse events have been reported by healthcare professionals from more than 900 health facilities in Thailand to the HPVC. The submission process can be either via an adverse event reporting form or via an online reporting system. Currently, Thai Vigibase has contained over 500,000 reports [13]. Until now, there have been only two published studies [14,15] using Thai Vigibase. Since Thai Vigibase has been considered a valuable source to look into adverse event reports among herbal products [14], characterizing patients and adverse events associated with 
andrographis can provide insights into a better understanding of this product safety profile. This retrospective database study aimed to describe characteristics of patients and hypersensitivity reactions associated with andrographis containing products using the Thai Vigibase database.

\section{Methods}

\section{Data source}

This retrospective database study used the Thai Vigibase which included all case reports of suspected adverse events submitted by healthcare professionals throughout the country to HPVC from February 2001 to December 2012. The case reports were obtained through either the spontaneous reporting system or intensive monitoring programmes [12]. Since this is an aggregate analysis of spontaneous reports of adverse events submitted to HPVC, there is minimal risk of patient confidentiality breaching. As we did not obtain the consent, we present specific cases with only general demographic characteristics to ensure patient identity anonymous. Permission for database access and publication of this work was granted by Thai FDA.

\section{Criteria for the selection of cases}

Reports with andrographis being the only suspected cause were selected. To be specific in final analysis, we investigated in details only those reports with terms consistent with constellation of hypersensitivity reactions [16] and considered critical terms according to WHO criteria [17].

\section{Data extraction}

All reports that indicated andrographis as the only suspected drug were retrieved. Of those reports, only ones that represented at least one hypersensitivity reaction [16] based on inclusion criteria were extracted. Finally, we matched hypersensitivity reaction with the WHO Adverse Reaction Terminology (WHO-ART) classification. According to WHO-ART classification, each preferred term is categorized into a primary system organ class and up to two subsidiary system organ classes [17]. We used the matched pair of the primary system organ class and preferred term in our analysis. A unique HPVC number identified each unique report. From each report, the following information was extracted: patient demographics, co-morbidities, suspected reactions, suspected drug as well as concomitant treatments, dosage,

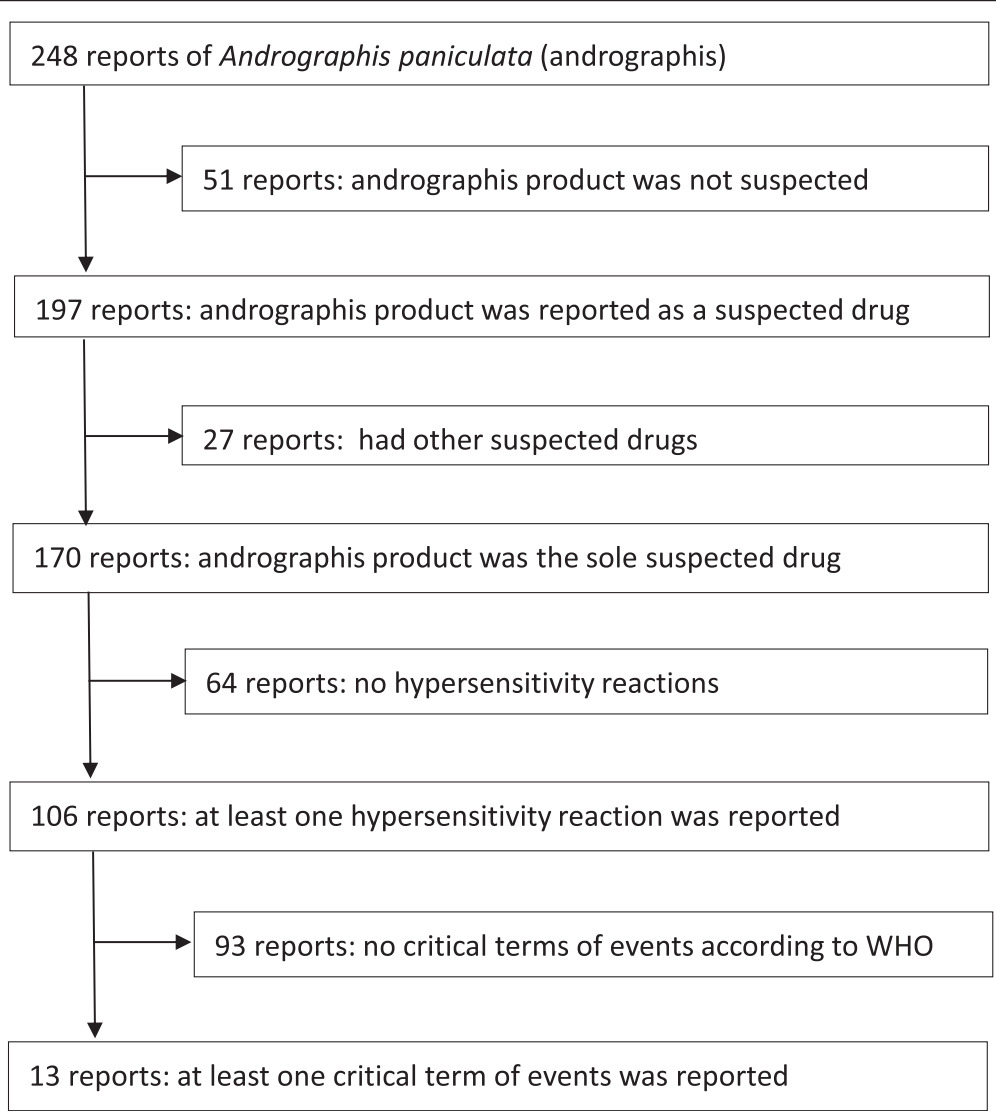

Figure 1 Flow diagram for case reports selection. 
Table 1 Characteristics of patients and adverse event reports among andrographis products users

Characteristics
Patients
Sex
Female
Male
Age [y], mean (SD) [min - max]
$<15$
$15-30$
$31-60$
$>60$
N/A

History of drug allergy

No

Yes

$\mathrm{N} / \mathrm{A}$

Adverse event reports

Source of reports

Spontaneous

Intensive

Seriousness

Serious
Hospitalization or prolongation
of hospitalization
Life threatening
Non-serious
Causality assessment ${ }^{\text {b }}$
Certain
Probable
Possible
Unlikely
N/A

No. of concomitant drug, mean (SD) [min - max]

None

litem

2items

3items

$\geq 4$ items

Time of exposure (day), mean (SD) [min - max]

$$
\begin{aligned}
& 1 \text { day } \\
& 2 \text { days } \\
& 3 \text { days } \\
& \geq 4 \text { days } \\
& \text { N/A }
\end{aligned}
$$

No. (\%) $[n=106]^{\mathrm{a}}$

$76(71.7)$
$30(28.3)$
$38.5(18.4)[8-80]$
$11(10.4)$
$26(24.5)$
$49(46.2)$
$11(10.4)$
$9(8.5)$
$93(87.7)$
$12(11.3)$
$1(1.0)$

95 (89.6)

$11(10.4)$

$18(17.0)$

16

2

$88(83.0)$

$8(7.5)$

$61(57.6)$

33 (31.1)

$0(0.0)$

$4(3.8)$

$0.4(0.8)$ [0 - 4]

82 (77.4)

$13(12.3)$

7 (6.6)

3 (2.8)

$1(0.9)$

$1.2(3.4)[0-30]$

51 (48.1)

20 (18.9)

14 (13.2)

\begin{tabular}{|c|c|}
\hline Time to onset (day), mean (SD) [min - max] & $0.8(1.6)[0-8]$ \\
\hline First day of use & $61(57.6)$ \\
\hline 2daysof use & $24(22.6)$ \\
\hline 3 days of use & $15(14.2)$ \\
\hline$\geq 4$ days of use & $5(4.7)$ \\
\hline N/A & $1(0.9)$ \\
\hline
\end{tabular}

8 (7.6)

13 (12.2)
Table 1 Characteristics of patients and adverse event reports among andrographis products users (Continued)

duration of andrographis treatment, date of adverse event onset, clinical outcome, causality assessment, and the source of reports. The seriousness of adverse event was classified as non-serious and serious events. For serious adverse events, they were sub-classified into hospitalization or prolongation of hospitalization, persistent or significant disability/incapacity, and life threatening. Data in Thai Vigibase were in the Oracle format.

\section{Data analyses}

The data were managed using Microsoft Excel ${ }^{\circ}$ and subsequently imported into $\mathrm{STATA}^{\circ}$ version 12.0 (StataCorp, College Station, Texas) for analysis. All variables were analyzed using descriptive statistics to determine total number of reports; mean age and number in each age group; percentage of gender, history of drug allergy, distribution of adverse events, source of reports, causality assessment, time of exposure, number of concomitant treatments, and time to onset of reaction.

\section{Results}

A total of 197 case reports of adverse events associated with Andrographis paniculata containing products were retrieved. In all reports, the herbal product was taken by mouth and was sole suspected drug in 170 case reports. A total of 106 cases reported term (s) consistent with constellation of hypersensitivity reactions (Figure 1).

Characteristics of 106 cases were provided in Table 1. Most of them (89.6\%) came from spontaneous reporting system. Age ranged from $8-80$ years with a mean age of $38.5 \pm 18.4$ years old and $71.7 \%$ were female. Almost half of them $(46.2 \%)$ were in 31-60 years age group. Eightyseven percent had no previously documented history of drug allergy. Only $17 \%$ (18 cases) were classified as serious with 16 cases requiring hospitalization. None of these resulted in death. For the causal relationship of reported event and the suspected herbal drugs, $57.6 \%$ were assessed as probable, followed by possible $31.1 \%$ and certain $7.5 \%$. Most of them (77.4\%) were no concomitant drug. Fortyeighth percent had time of exposure less than 1 day. The 
reactions had developed in the first day of administration in $57.6 \%$ of case reports and $22.6 \%$ on the second days of use. The reported adverse events were shown in Table 2.

Out of 106 case reports, a total of 13 case reports were included for detail case description since their reactions were hypersensitivity reactions considered critical term according to WHO criteria. Adverse events included anaphylactic shock (5), anaphylactic reaction (4) and angioedema (5). The average age was 38.9 years old. Most of them $(10 / 13,76.9 \%)$ were female. Details of each case including adverse event reports were shown in Table 3. A history of drug allergy was present in two patients who developed angioedema. One patient was allergic to tetracycline, while another one was allergic to ibuprofen. The onset ranged from 5 minutes to 1 day. Most of them (11 case reports) were serious. The probability of causality assessment was certain (3), probable (7) and possible (1). Of 13 case reports, 7 case reports indicated the product's brand name. Most importantly, 6 brands were reported among the 7 case reports. After checking each brand name, all of them are dry powder with different doses ranging from $352 \mathrm{mg}$ to $1,750 \mathrm{mg}$.

\section{Discussion}

Our study is the first report accumulating a number of case reports with hypersensitivity reactions especially anaphylactic reactions among andrographis users in Thailand. Our findings indicated that the oral use of andrographis may be associated with a risk of acute hypersensitivity reactions. However, it was not possible to draw a direct causal relation from this study. There remains a strong need warranting a further study to investigate this association in the future.

Even though andrographis had long been used as traditional medicines particularly in Southeast Asia, e.g. India, Thailand, there has been limited report about hypersensitivity reaction associated with andrographis. To the best of our search, there was only one study [18] reporting a case of anaphylactic reaction among an HIV patient. This study was conducted in 13 HIV positive patients and 5 uninfected health-volunteer to evaluate adverse events of escalating dosages. At the elevated dose of andrographis (6-12 times higher than usual dose), a case of HIV patient experienced an anaphylactic reaction during week 4 and stopped medication. It is not uncommon to expect such adverse event when any particular product is given in such circumstance. It was important to note that there was no mention on the mechanism of such hypersensitivity reaction.

The number of cases reports of hypersensitivity analysis among andrographis users in this study was 106, which was much higher than 17 cases reported in the first document describing the international experiences in pharmacovigilance network [2]. In addition, these reports were submitted from various settings with differing brand products. This cumulative evidence suggested that andrographis was potentially associated with hypersensitive reactions as it was the likely cause for the majority of cases.

It is important to note that all case reports in this study used andrographis containing product as a single agent. This is very different from others [2]. Farah et al. [2] described 17 reports of hypersensitivity reactions

Table 2 Adverse events classified by organ system according to WHO Adverse Reaction Terminology

\begin{tabular}{|c|c|c|}
\hline System organ class & No. $(\%)[n=243]^{a}$ & Preferred term(n) \\
\hline Skin and appendages disorders & $126(51.85)$ & $\begin{array}{l}\text { Urticaria (37), rash maculo-papular (31), rash (18), pruritus (16), rash erythematous (8), } \\
\text { dermatitis exfoliative (1), skin exfoliation (2), Steven Johnson syndrome (1), sweating } \\
\text { increased (2), acute generalized exanthematous pustulosis (1), bullous eruption (1), } \\
\text { eosinophillia (1), fixed eruption (1), stomatitis ulcerative (1), purpura allergic (1), flushing (1) }\end{array}$ \\
\hline Body as a whole-general disorders & $57(23.46)$ & $\begin{array}{l}\text { Face oedema (19), angioedema (4), anaphylactic shock(5), anaphylactic reaction (4), } \\
\text { fatigue (6), oedema mouth (5), fever (3), chest pain (3), oedema (2), oedema periorbital } \\
\text { (1), therapeutic response decreased (2), back pain (1), oedema peripheral(3), pain(1) }\end{array}$ \\
\hline Gastrointestinal system disorders & $22(9.05)$ & $\begin{array}{l}\text { Nausea (8), vomiting (4), abdominal pain (2), diarrhea (1), gastro-intestinal } \\
\text { disorder non-specific (1), lipsdry (1), stomatitis (1), melaena (1), mouth dry (1) }\end{array}$ \\
\hline Respiratory system disorders & $15(6.17)$ & Dyspnoea (6), coughing (6), bronchospasm (2), sputum increased (1) \\
\hline Psychiatric disorders & $8(3.29)$ & Anorexia (4), somnolence (3), insomnia(1) \\
\hline $\begin{array}{l}\text { Central and peripheral nervous } \\
\text { system disorders }\end{array}$ & $7(2.88)$ & Headache (3), dysaethesia (2), dizziness(2) \\
\hline Musculoskeleton system disorders & $3(1.23)$ & Muscle weakness (2), paralysis (1) \\
\hline Vascular (extra cardiac) disorders & $1(0.41)$ & Vasculitis (1) \\
\hline Liver and biliary system disorders & $1(0.41)$ & Hepatitis(1) \\
\hline Urinary system disorders & $1(0.41)$ & Urinary frequency (1) \\
\hline Various & $2(0.82)$ & Anaesthesia local (1), anaesthesia mouth(1) \\
\hline
\end{tabular}

${ }^{a}$ Number of events from 106 case reports (some reports have more than one event).

Bold indicates hypersensitivity reactions with critical term. 
Table 3 Hypersensitivity reactions with critical term among patients using andrographis product

\begin{tabular}{|c|c|c|c|c|c|c|c|c|c|}
\hline \multirow[b]{2}{*}{ Case no. } & \multicolumn{3}{|l|}{ Product } & \multicolumn{5}{|c|}{ Adverse event/symptom } & \multirow[b]{2}{*}{ Outcome } \\
\hline & Drug & Type $^{a}$ & Dosage & Adverse event & Details & Onset & Seriousness & $\begin{array}{l}\text { Causality } \\
\text { assessment }\end{array}$ & \\
\hline 1 & andrographis (325 mg/cap) & S & 5 сар $\mathrm{PO}, \mathrm{OD}$ & anaphylactic shock & $\begin{array}{l}\text { Angioedema, } \\
\text { urticaria, BP 90/60 }\end{array}$ & $30 \mathrm{~min}$ & $\begin{array}{l}\text { serious (hospitalization or } \\
\text { prolongation of hospitalization) }\end{array}$ & Certain & $\begin{array}{l}\text { Complete recovery } \\
\text { without lesion }\end{array}$ \\
\hline \multirow[t]{3}{*}{2} & andrographis (352 mg/cap) & S & 3 cap 1 time used & anaphylactic shock & Urticaria, BP 87/73 & 1 day & $\begin{array}{l}\text { serious (hospitalization or } \\
\text { prolongation of hospitalization) }\end{array}$ & Probable & $\begin{array}{l}\text { Complete recovery } \\
\text { without lesion }\end{array}$ \\
\hline & paracetamol (500 mg) & O & 1 tab PO, OD & & & & & & \\
\hline & chlorpheniramine (4 mg) & O & 1 tab PO, TID & & & & & & \\
\hline \multirow[t]{2}{*}{3} & andrographis & s & 2 cap 1 time used & anaphylactic shock & Urticaria, BP 90/70 & $30 \mathrm{~min}$ & $\begin{array}{l}\text { serious (hospitalization or } \\
\text { prolongation of hospitalization) }\end{array}$ & Probable & $\begin{array}{l}\text { Complete recovery } \\
\text { without lesion }\end{array}$ \\
\hline & paracetamol (500 mg) & O & 2 tab PO, prn & & & & & & \\
\hline 4 & andrographis & s & 2 cap 1 time used & anaphylactic shock & $\begin{array}{l}\text { Oedema, uticaria, } \\
\text { chest pain, BP 130/70 }\end{array}$ & 1 day & $\begin{array}{l}\text { serious (hospitalization or } \\
\text { prolongation of hospitalization) }\end{array}$ & Probable & $\begin{array}{l}\text { Complete recovery } \\
\text { without lesion }\end{array}$ \\
\hline 5 & andrographis (352 mg/cap) & s & 1 cap PO, TID & anaphylactic shock & $\begin{array}{l}\text { Puffy eyelid, lung } \\
\text { wheezing, drowsiness, } \\
\text { BP } 80 / 50\end{array}$ & 1 day & serious (life threatening) & Certain & $\begin{array}{l}\text { Complete recovery } \\
\text { without lesion }\end{array}$ \\
\hline 6 & andrographis & s & $1750 \mathrm{mg} 1$ time used & anaphylactic reaction & $\begin{array}{l}\text { Urticaria, sweat increased, } \\
\text { nausea, BP 96/59 }\end{array}$ & $10 \min$ & $\begin{array}{l}\text { serious (hospitalization or } \\
\text { prolongation of hospitalization) }\end{array}$ & Probable & $\begin{array}{l}\text { Complete recovery } \\
\text { without lesion }\end{array}$ \\
\hline 7 & andrographis & S & $350 \mathrm{mg} \mathrm{PO}, 1$ time used & anaphylactic reaction & $\begin{array}{l}\text { anaphylactic reaction, } \\
\text { BP 120/80 }\end{array}$ & $45 \min$ & serious (life threatening) & Probable & $\begin{array}{l}\text { Complete recovery } \\
\text { without lesion }\end{array}$ \\
\hline 8 & andrographis & s & 400 mg 2 time used & anaphylactic reaction & $\begin{array}{l}\text { Oedema eyelid, wheezing, } \\
\text { rash, BP 153/101 }\end{array}$ & $16 \mathrm{hr}$ & $\begin{array}{l}\text { serious (hospitalization or } \\
\text { prolongation of hospitalization) }\end{array}$ & Probable & $\begin{array}{l}\text { Complete recovery } \\
\text { without lesion }\end{array}$ \\
\hline 9 & andrographis & S & 2 cap PO, 1 time used & anaphylactic reaction & $\begin{array}{l}\text { Urticaria, rash, chest } \\
\text { tightness, , tachycardia }\end{array}$ & $5 \mathrm{~min}$ & $\begin{array}{l}\text { serious (hospitalization or } \\
\text { prolongation of hospitalization) }\end{array}$ & Probable & $\begin{array}{l}\text { Complete recovery } \\
\text { without lesion }\end{array}$ \\
\hline 10 & andrographis & S & 4 сар PO, TID & angioedema & Angioedema, urticaria & 1 day & Non-serious & Certain & $\begin{array}{l}\text { Complete recovery } \\
\text { without lesion }\end{array}$ \\
\hline \multirow[t]{3}{*}{11} & andrographis & s & 3 сар PO, TID & angioedema & - & 1 day & Non-serious & Possible & $\begin{array}{l}\text { Complete recovery } \\
\text { without lesion }\end{array}$ \\
\hline & guaifenesin (100 mg) & $\mathrm{O}$ & 1 tab PO, TID & & & & & & \\
\hline & Salbutamol (4 mg) & $\mathrm{O}$ & 1 tab PO, TID & & & & & & \\
\hline \multirow[t]{4}{*}{12} & andrographis & s & N/A & angioedema & - & N/A & Non-serious & Possible & $\begin{array}{l}\text { Complete recovery } \\
\text { without lesion }\end{array}$ \\
\hline & ranitidine & O & N/A & & & & & & \\
\hline & hydrochlorothiazide & $\mathrm{O}$ & N/A & & & & & & \\
\hline & Curcuma longa Linn. & $\mathrm{O}$ & N/A & & & & & & \\
\hline 13 & andrographis & S & N/A & angioedema & - & 1 day & Non-serious & Probable & $\begin{array}{l}\text { Still has some } \\
\text { symptom }\end{array}$ \\
\hline
\end{tabular}


including 7 anaphylaxis, and specified that the case reports consist of both single agent and combination of agents in products containing andrographis. It was suggested that the use andrographis as a single agent or purified form as andrographolide should be prohibited. Calabrese et al. [18] hypothesised that this herb has been used in combination with other herbs, perhaps to ameliorate potential adverse effects from andrographis.

The issue of reporting of hypersensitivity reactions among andrographis users has caught attention of Thai FDA. The Signal Detection and Assessment Working Group and Drug Safety (pharmacovigilance) subcommittee under Thai FDA decided to make no changes on product labelling because the causation could not be confirmed. The report of potential association was disseminated through HPVC (Health Products Vigilance Center) safety news. In addition, Thai FDA recommends a pharmacoepidemiology study to determine whether the association between hypersensitivity reactions and andrographis containing products is confirmed.

An important limitation of current evidence is the lack of direct causation. Our study cannot eliminate a possibility that hypersensitivity reaction might be related to product contamination and its lack of standardization across brands. Even though the evidence presented in this article is substantiated with a large number of case reports submitted from various settings with differing brand products, there remains no direct causation study that can make such a conclusive remark.

\section{Conclusion}

In summary, our findings demonstrated that hypersensitivity reactions have been reported among patients receiving Andrographis paniculata. Healthcare professionals should be aware of this potential risk. Further investigation of the causal relationship is needed.

\section{Competing interests}

The authors declare that they have no competing interests.

\section{Authors' contributions}

All authors made substantial contributions to conception, design, and drafting the manuscript. SS conducted the analysis. WS, UP, NC conducted a critical review of the manuscript and provided final editing to the manuscript. All authors read and approved the final manuscript.

\section{Acknowledgements}

We thank the Health Product Vigilance Center, Food and Drug Administration, Ministry of Public Health, Thailand for providing helpful support on data access and their valuable inputs for the manuscript.

\section{Funding}

No sources of funding were used to conduct this study or prepare this manuscript.

\section{Author details}

${ }^{1}$ Health Product Vigilance Center (HPVC), Food and Drug Administration, Ministry of Public Health, Bangkok, Thailand. ${ }^{2}$ Center of Health Outcomes Research and Therapeutic Safety (COHORTS), School of Pharmaceutical Sciences, University of Phayao, Phayao, Thailand. ${ }^{3}$ Center of Pharmaceutical
Outcomes Research (CPOR), Department of Pharmacy Practice, Faculty of Pharmaceutical Sciences, Naresuan University, Phitsanulok, Thailand. ${ }^{4}$ Pharmacotherapy Outcomes Research Center (PORC), College of Pharmacy, University of Utah, Salt Lake City, UT, USA. ${ }^{5}$ Department of Pharmaceutical Care, Faculty of Pharmacy, Chiang Mai University, Chiang Mai, Thailand. ${ }^{6}$ School of Pharmacy, Monash University Malaysia, Selangor, Malaysia. ${ }^{7}$ School of Population Health, University of Queensland, Brisbane, QLD, Australia. ${ }^{8}$ School of Pharmacy, University of Wisconsin-Madison, Madison, WI, USA.

Received: 14 January 2014 Accepted: 10 December 2014

Published: 24 December 2014

\section{References}

1. Coon JT, Ernst E: Andrographis paniculata in the treatment of upper respiratory tract infections: a systematic review of safety and efficacy. Planta Med 2004, 70:293-298.

2. Farah M, Meyboom R, Ploen M: Acute hypersensitivity reactions to Andrographis paniculata containing products, as reported in international pharmacovigilance. Drug Saf 2008, 31(10):885.

3. National Drug Committee: National List of Essential Drug A.D.1999 (List of herbal medicine products). Thailand: The Agricultural Co-Operative Federation of Thailand; 1999.

4. National Drug Committee: List of Herbal Medicine Products A.D.2006. Thailand: The Agricultural Co-Operative Federation of Thailand; 2006.

5. National Drug Committee: List of Herbal Medicine Products A.D.2011. Thailand: The War Veterans Organization of Thailand Under Royal Patronage of His Majesty the King; 2011

6. Oppamayun Y, Rungapiromnan W, Suwankesarong W, Urchaikul C: Intensive safety monitoring on Thai Herbal National Essential Drug List 1996. In Thailand: Thai Food and Drug Administration; 2010.

7. Health Product Vigilance Center: The Result of Intensive Monitoring Program of National List of Essential Drugs A.D. 1999 (List of herbal medicine products). Thailand: Thai Food and Drug Administration; 2005.

8. Wysowski DK, Swartz L: Adverse drug event surveillance and drug withdrawals in the United States, 1969-2002: the importance of reporting suspected reactions. Arch Intern Med 2005, 165:1363-1369.

9. Wise L, Parkinson J, Raine J, Breckenridge A: New approaches to drug safety: a pharmacovigilance tool kit. Nat Rev Drug Discov 2009, 8:779-782.

10. Kunac DL, Harrison-Woolrych M, Tatley MV: Pharmacovigilance in New Zealand: the role of the New Zealand Pharmacovigilance Centre in facilitating safer medicines use. N Z Med J 2008, 121:76-89.

11. Edwards IR: Pharmacovigilance. Br J Clin Pharmacol 2012, 73:979-982.

12. The Thai Food and Drug Administration, Ministry of Public Health: Pharmacovigilance in Thailand. In Pharmacovigilance: Partnership for Patient Safety. Bangkok: 2008. July 2-3.

13. Spontaneous reports of adverse drug reaction. 2008, [http://thaihpvc.fda. moph.go.th/thaihvc/Public/News/uploads/hpvc_1_3_4_100410.pdf]

14. Saokaew S, Suwankesawong W, Permsuwan U, Chaiyakunapruk N: Safety of herbal products in Thailand: an analysis of reports in the thai health product vigilance center database from 2000 to 2008. Drug Saf 2011, 34:339-350

15. Boonmuang P, Nathisuwan S, Chaiyakunapruk N, Suwankesawong W, Pokhagul P, Teerawattanapong N, Supsongserm P: Characterization of statin-associated myopathy case reports in Thailand using the health product vigilance center database. Drug Saf 2013, 36(9):779-78716.

16. Peakman M, Vergani D: Basic and clinical immunology. 2nd edition. Edinburgh; New York: Elsevier/Churchill Livingstone; 2009

17. Lindquist M: VigiBase, the WHO global ICSR database system: basic facts. Drug Infor J 2008, 42:409-419.

18. Calabrese C, Berman SH, Babish JG, Ma X, Shinto L, Dorr M, Wells K, Wenner CA, Standish L: A phase I trial of andrographolide in HIV positive patients and normal volunteers. Phytother Res 2000, 14(5):333-338.

doi:10.1186/1472-6882-14-515

Cite this article as: Suwankesawong et al:: Characterization of hypersensitivity reactions reported among Andrographis paniculata users in Thailand using Health Product Vigilance Center (HPVC) database. BMC Complementary and Alternative Medicine 2014 14:515. 